\title{
(2) OPEN ACCESS \\ How to communicate with families living in complete isolation
}

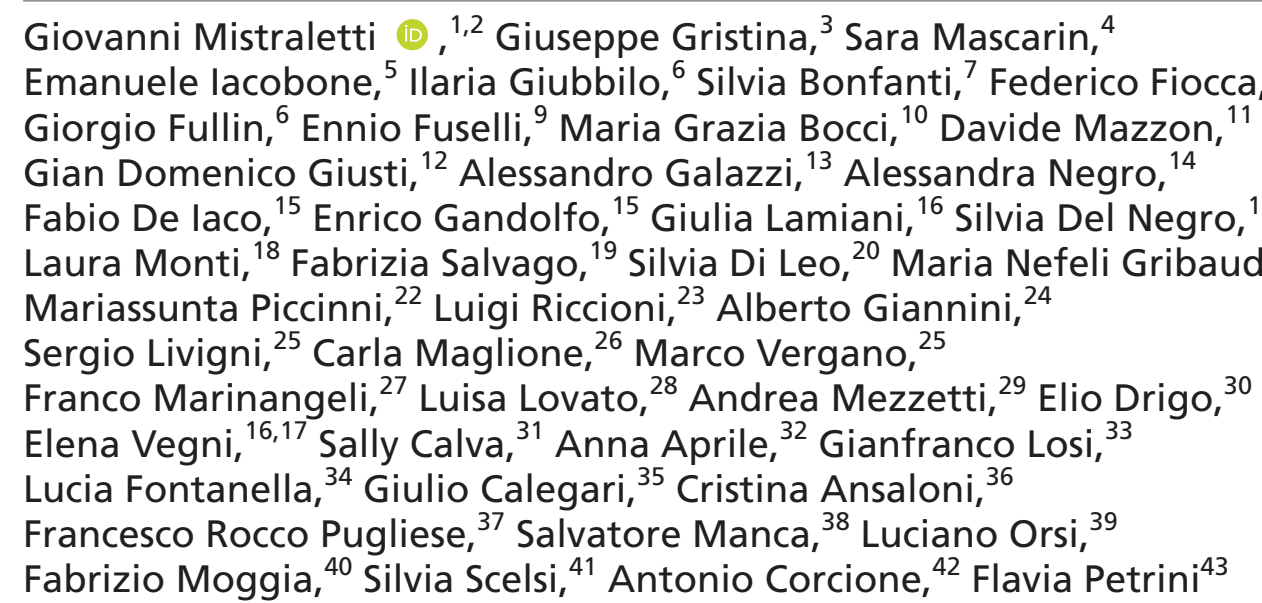

For numbered affiliations see end of article.

\section{Correspondence to}

Dr Giovanni Mistraletti, Dipartimento di Fisiopatologia Medico-Chirurgica e dei Trapianti, Università degli Studi di Milano, 20142 Milano, Italy; giovanni.mistraletti@unimi.it

Received 13 August 2020 Accepted 25 August 2020

\section{Check for updates}

(C) Author(s) (or their employer(s)) 2020. Re-use permitted under CC BY-NC. No commercial re-use. See rights and permissions. Published by BMJ.

\footnotetext{
To cite: Mistraletti $\mathrm{G}$, Gristina G, Mascarin S, et al. BMJ Supportive \& Palliative Care Epub ahead of print: [please include Day Month Year]. doi:10.1136/ bmjspcare-2020-002633
}

\section{ABSTRACT}

Importance During the SARS-CoV-2 pandemic, a complete physical isolation has been worldwide introduced. The impossibility of visiting their loved ones during the hospital stay causes additional distress for families: in addition to the worries about clinical recovery, they may feel exclusion and powerlessness, anxiety, depression, mistrust in the care team and post-traumatic stress disorder. The impossibility of conducting the daily meetings with families poses a challenge for healthcare professionals. Objective This paper aims to delineate and share consensus statements in order to enable healthcare team to provide by telephone or video calls an optimal level of communication with patient's relatives under circumstances of complete isolation.

Evidence review PubMed, Cochrane Database of Systematic Reviews, Database of Abstracts and Reviews of Effectiveness and the AHCPR Clinical Guidelines and Evidence Reports were explored from 1999 to 2019. Exclusion criteria were: poor or absent relevance regarding the aim of the consensus statements, studies prior to 1999, non-English language. Since the present pandemic context is completely new, unexpected and unexplored, there are not randomised controlled trials regarding clinical communication in a setting of complete isolation. Thus, a multiprofessional taskforce of physicians, nurses, psychologists and legal experts, together with some family members and former intensive care unit patients was established by four Italian national scientific societies. Using an e-Delphi

\section{Key points}

Question

- What is the best way for doctors and nurses to communicate with family members under circumstances of complete isolation such as during SARS-CoV-2 pandemic?

\section{Findings}

- Ten consensus statements and two practical checklists for phone or video calls were obtained from a multidisciplinary task force through an e-Delphi consensus procedure.

\section{Meaning}

- The statements and the checklists may represent helpful tools for ensuring a good quality in clinical communication between healthcare team and families living in complete isolation.

methodology, general and specific questions were posed, relevant topics were argumented, until arriving to delineate position statements and practical checklist, which were set and evaluated through an evidence-based consensus procedure.

Findings Ten statements and two practical checklists for phone or video calls were drafted and evaluated; they are related to who, when, why and how family members must be given clinical information under circumstances of complete isolation.

Conclusions and relevance The statements and the checklists offer a structured 
methodology in order to ensure a good-quality communication between healthcare team and family members even in isolation, confirming that time dedicated to communication has to be intended as a time of care.

\section{INTRODUCTION}

The global emergency caused by the SARS-CoV-2 pandemic has suddenly changed how we communicate with patients and their families. ${ }^{1}$ Healthcare professionals are isolated from their families and forced to manage the consequences of this isolation just like the patients. Patients and their relatives perceive not only the clinical results but also the personal attitudes, closeness and psychological support from care teams. ${ }^{2}$ This perception of genuine participation by the healthcare professionals is especially important when a patient dies, and may influence the whole process of grief. ${ }^{3}$

Thus, a multiprofessional taskforce was created by four national scientific societies in April 2020: the Italian Society of Anesthesia and Intensive Care, the Italian Society of Critical Care Nurses, the Italian Society of Emergency Medicine and the Italian Society of Palliative Care, which principal characteristics are described in the online supplemental material table S1. The aim was to formulate a position paper intended for all healthcare professionals caring for patients with CoViD-19, particularly those in more severe conditions, to help the care team in communicating with families living in complete isolation. The full version of the position paper is available as online supplemental appendix of the present paper.

\section{METHODS}

The spread of the SARS-CoV-2 has generated an unprecedented pandemic in modern medicine. There are no randomised controlled trials nor metaanalyses regarding clinical communication in settings of complete isolation, or in a condition of imbalance between demand and supply of healthcare resources. Thus, considering the available scientific evidence ${ }^{4}$ and the guidelines ${ }^{5-7}$ currently existing, mainly referring to similar settings, and all information from collegues with direct experience in the treatment of CoViD-19 patients, the authors used a modified e-Delphi method described below to draft the shared recommendations.

\section{Creating an interdisciplinary working group}

In 2 April 2020, the steering committee of the Intensiva 2.0 Project $^{8}$ (a network of 335 Italian intensive care units (ICUs), including intensivists physicians and nurses actively involved in the field of clinical communication), has been mandated by the SIAARTI National Executive Committee to develop recommendations regarding how to communicate with families of patients affected by CoViD-19 with or without acute respiratory failure, admitted in intensive or subICUs in complete isolation.
Based on the new interdisciplinary approach imposed by the unprecedented working practices required by $\mathrm{CoViD}-19$, the members of the Intensiva 2.0 steering committee first asked to the National Executive Committees of three other Scientific Societies above mentioned to formally include their representative members, specially selected among those most experienced in the field of communication, to form a joint task force aimed to draw up the shared recommendations and to write a position paper. The interdisciplinary working group (IWG) was then effective from 4 April 2020.

\section{Building the experts panel}

According to the e-Delphi procedure, to ensure a comprehensive argumentation, an experts panel was recruited by the IWG covering the characteristics relevant to the theme of communication in isolation and its future perspective. The specific fields of necessary expertise were identified through a PESTEL framework analysis. ${ }^{9}$

The six general perspectives were modifyed accordingly with the topics of main interest as follows:

- Political: how the mesures adopted by the Italian government to fighting the pandemic have affected the relationship between doctors, patients and their families?

- Economic: is there a financial burden caused by the new ways (smartphone and tablets for patients) to communicate in isolation?

- Social: what are emerging social issues (healthcare system organisation strengths and weaknesses, linguistic and/or psychological, cultural, religious issues)?

- Technological: what technological innovations could affect the subject of communication in isolation?

- Environmental: what surrounding conditions influence our subject?

- Legal: could specific aspects or changes in legislation impact the new organisation for communicating in isolation?

The experts panel, consisting of 46 members, was established as a task force from 6 April 2020. Participants were splitted in two, between lead authors and expert reviewers accordingly to personal competencies, previous experiences and actual availability. Extreme rapidity was used in creating this task force, since many physicians and other healthcare allied were asking clear indications to communicate during complete isolation, and the Italian hospitals were overwhelmed because of the pandemic peak: the four Scientific Societies required then to proceed with the utmost speed to write a shared document. The complete description of the members of the CommuniCoViD task force is presented in the online supplemental file 2.

In a web conference the task force, using the SWOT analysis, ${ }^{10}$ identified first:

- Strengths: all factors allowing the caring teams to produce better performances in communicating in isolation with patients and their families. 
- Weaknesses: the areas where the caring teams need, in contrast, to improve.

- Opportunities: the external factors that could support the caring teams to achieve the difficult goal to communicate in a way as better as possible.

- Threats: all factors that have the potential to prevent the caring teams to communicate in isolation with patients and families as effectively and efficiently as possible.

\section{Building the queries}

In relation to the outcomes deriving from the SWOT analysis, during two further web conferences, the task force identified the five fundamental aims of communication with family members. Through the related topics debated next, two general questions and five specific questions, relevant for drafting the shared statements and the checklists, were identified.

In building the modified e-Delphi process, the primary questions a priori established were devoted: (1) to find the general reasons leading the need for communication with families living in complete isolation and (2) to create the consensus statements and the checklists for daily clinical practice.

Questions about communication in general:

1. What are the goals of communication?

2. What are the special attentions to be had in time of complete isolation?

Questions leading the building of consensus statements:

1. When is it opportune to make the communication with families in complete isolation?

2. Who has to communicate with family members of isolated patients?

3. What instruments can be used for clinical communication in complete isolation?

4. What are the essential contents of the clinical communication in complete isolation?

5. How to operatively make a phone call/video call for clinical communication in complete isolation?

Figure 1 provides a comprehensive work plan summarising all the above-mentioned procedures regarding the consensus statements. A similar procedure was then adopted to build a checklist for making a telephone/video call during isolation. Lastly, a consensus evaluation was done on the contents of each statement and on a phone call checklist.

\section{Executing the consensus on statements rounds}

The statements for the communication with family members in complete isolation and the checklist for telephone call items presented here, summarize the shared answers made by the task force during the web conferences: each member explicited an agreement, by rating each statement and each phone call item, contemporarily with the other task force members (1=strong disagreement, 2 =disagreement, $3=$ neutral, $4=$ agreement, $5=$ strong agreement). Consensus ratings for both statements and checklist for telephone call items are reported in figures 2 and 3, and are expressed as mean \pm SD.
At the end of the procedure, the document CommuniCoViD was approved by the National Executive Commitees of the four Scientific Societies involved, and sent to the Society members in 18 April 2020 (see in online supplemental appendix for the document full version).

\section{RESULTS}

\section{Aims of communication and related topics}

The pillars of effective communication are truthfulness, consistency and gradualness. ${ }^{11}$ Clinical communication with families has five essential aims:

- Give understandable information about the disease and treatment options.

- Obtain information on the relatives' expectations and the patient's values and choices.

- Show empathy and participation.

- Allow relatives to express their emotions.

- Prevent misunderstandings and conflicts with the care team.

Each aim is grounded on specific consideratons, agreed by the authors, which are discussed below.

Relational aptitude

In a pandemic, establishing effective communication between healthcare professionals and patients is a difficult task because the need to use personal protective equipment (PPE) impedes recognition and limits non-verbal communication. Despite these limitations, professionals are required to play the relational role normally performed ${ }^{12}$ by relatives, even in case of the patient's death. Talking to a relative on the phone is also complicated ${ }^{13}$ and some family members are not able to use video call technology. ${ }^{14}$

Preparing for communication

In an emergency, the accessibility of information must be prioritised. Checking information comprehension has been proven to provide reassurance to relatives and staff. All team members involved in communication have to pay the utmost attention in avoiding ambiguous messages, especially since the therapeutic value of commucation is severely limited because of the lack of non-verbal components. ${ }^{15}$ Supporting the relatives and offering honest and motivating feedback to collegues, enables healthcare professionals to pursue their care work: communication, compassion, promoting quality of life, and, where possible, healing.

Justice during a pandemic

In case of a large imbalance between demand and supply of healthcare resources, ${ }^{16} 17$ clinical choices can be modified in accordance with ethical recommendations and local pandemic plans. ${ }^{18}$ During communication with family members, all clinical and organisational efforts to deliver the most adequate treatments have to be underlined. 


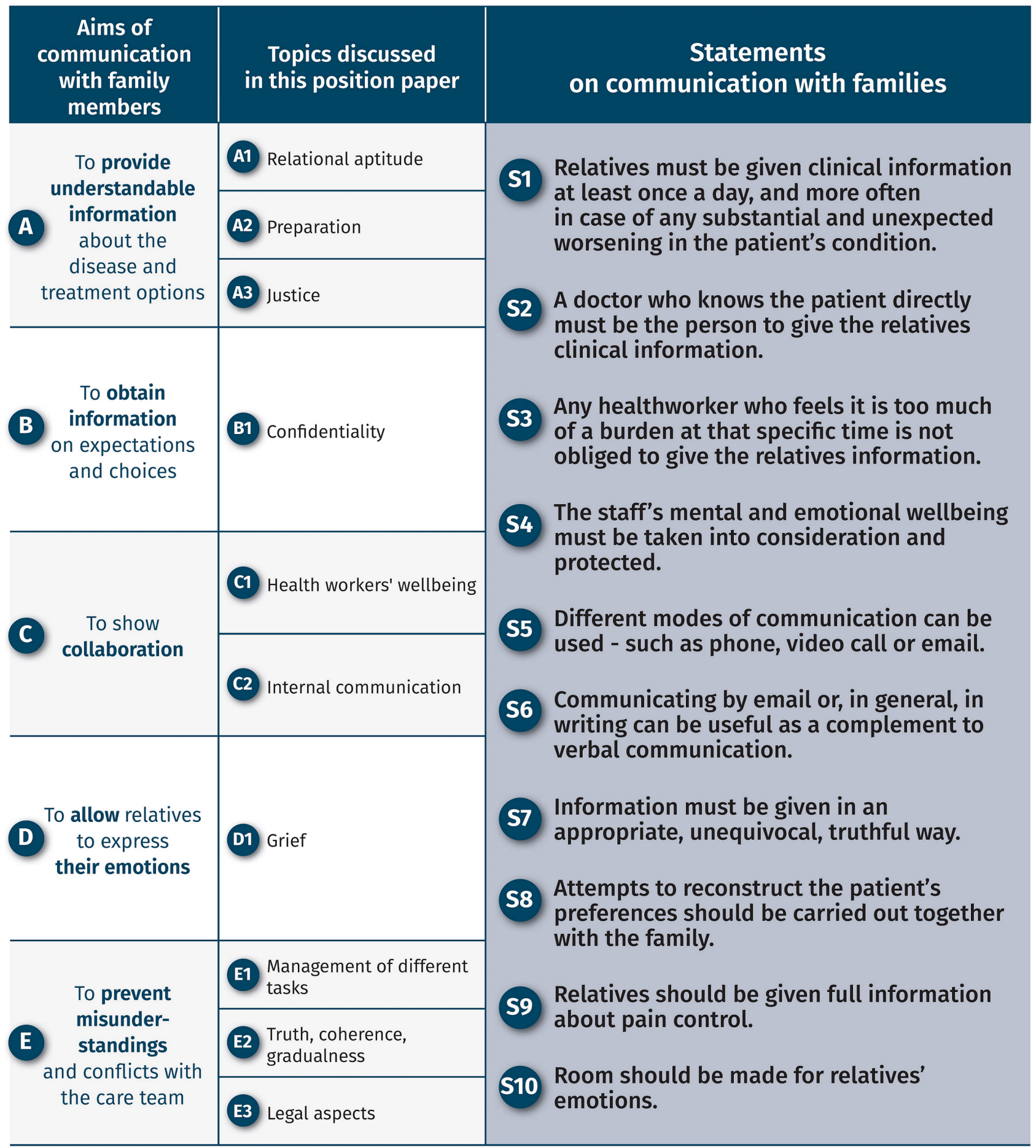

Figure 1 Synthesis of the eDelphi process results.

\section{Confidentiality}

Paying attention to professional confidentiality builds trust in the care team. ${ }^{19}$ In isolation, visual communication by video systems is helpful to combat the inevitable lonelyness. For this reason it is preferable, when possible, to make video calls between doctors and family members, rather than a simple phone call. Video calls between patients and relatives may be encouraged.
Protecting the healthcare professionals' psychological well-being

During a pandemic, protecting healthcare professionals' psychological well-being is crucial. Insomnia, flashbacks, intrusive thoughts betray post-traumatic stress disorder. In a condition of limited resources, the best possible behaviour may not coincide with one's ethical and professional values, triggering moral distress (due to having to solve an ethical conflict). Psychologists should maintain constant contact with 


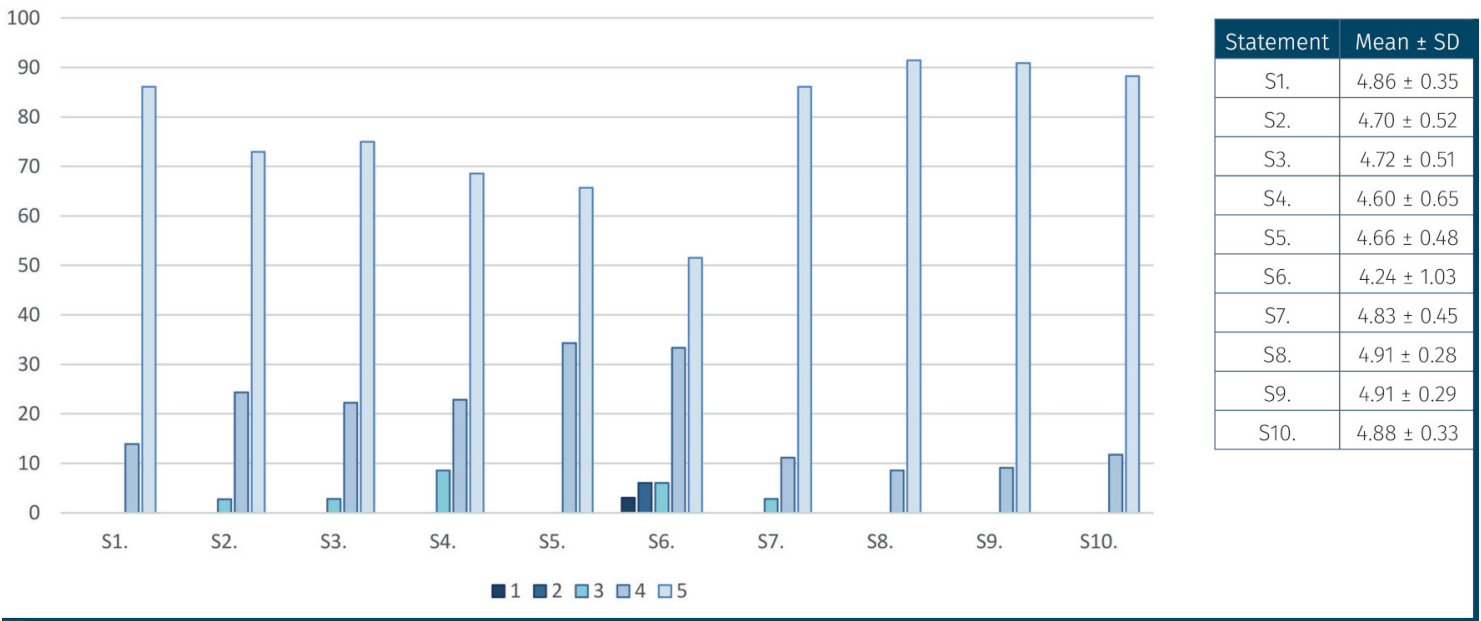

Figure 2 Consensus ratings on statements for communicating with family members in isolation.

healthcare professionals. ${ }^{20}$ Additionally, debriefing and defusing meetings involving all staff may be helpful.

Internal communication

In a pandemic, clinical uncertainty, PPE obstructing movement, fake news bombing, the fear of contagion, the distance from and fear for one's family reduce emotional relief. A structured chain of command is a proven support for professionals. Internal communication oriented towards therapeutic successes and reduced numbers of ICUs admissions may help to establish a positive climate among staff members.

Grief

In isolation, elaboration of grief may be limited due to restrictions on funeral services. ${ }^{21} 22$ Family members cannot visit their dying relative, but we can describe to them the final moments of their loved one's life. ${ }^{23}$ In order to establish rapport with the family, healthcare professionals can focus on particular strategies with which they feel comfortable. Informing on the specific procedures applied after the patient's death is mandatory. Religious assistance must always be offered.
Compatibility of the different tasks

A dedicated time should be assigned to the communication as a part of care. If family information cannot take place immediately, it must be allowed as soon as possible. Frequently the same healthcare worker communicates with the family, makes decisions regarding the allocation of resources, and is responsible for clinical and organisational management. The hospital managers should help to ease the emotional burden deriving from this overload by distributing these tasks to different healthcare professionals, whenever possible.

The content of the communication

The content of the clinical information communicated should be based on respect for patient autonomy, confidentiality of the doctor-patient and family relationship, and an assessment of the family's desire and need for information. In communicating bad news, the truth must be honestly coveyed but this does not necessarily require going into great detail. Decisions to withhold or withdraw treatments must be inspired

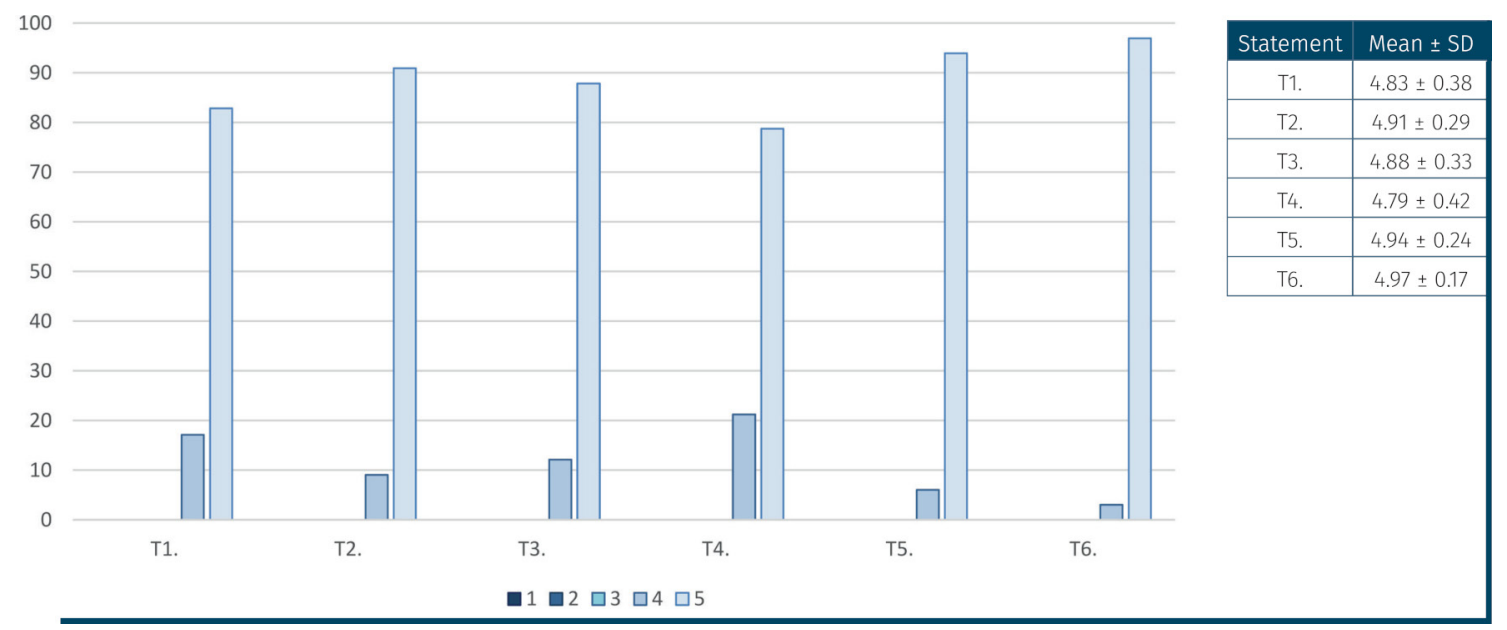

Figure 3 Consensus ratings on checklist items for telephone call. 
by clinical and ethical principles and communicated honestly, clearly and unequivocally. ${ }^{24-27}$

Communication to family members: the legal aspects

In the case of competent patients in isolation, consent to treatments and the processing of personal data is required together with the name of a family member authorised to receive medical information and choices among technological tools for communicating. If the patient can no longer communicate, it is essential that medical staff promptly collect the wishes regarding present and future treatments. If the patient is already incompetent, in the absence of their healthcare proxy or legal representative or advance directives/ advance care planning (in Italy according to legislation no.219/2017), ${ }^{28}$ communication with family members is necessary even if they cannot decide in the patient's place. If the patient is incompetent or legally unable to give their own consent, processing personal data regarding their healthcare is considered legitimate when it is necessary to protect the patient's life ${ }^{29}$ keeping in mind the principles of necessity, proportionality and adequacy. ${ }^{30}$

\section{Statements on communication with families}

Through an in-depth discussion amidst authors about the content of any single topic reported above, ten statements were finally drawn up. Among them, there is an overlap between some widespread messages, already published and deeply discussed elsewhere, and some new messages, highlighted by the clinical context due to the pandemic condition. The authors decided to consider both because even the recommendations generic and not specific to CoViD-19 were considered having higher relevance in a scenario of complete isolation. The statements S1, S2, S7, S8, S9 and S10 are based on recommendation already published and not specific for CoViD-19 patients. The statements S3, S4, S5 and S6, together with the two checklists for phone and video calls, are completely new and developed in the unique CoViD-19 isolation scenario.

In any cases, all recommendations and checklists apply to all patients admitted during isolation. Until family members will be not once again allowed to return into the ICUs, and in general into the hospital wards, the present recommendations will have a great importance, both for CoViD-19 and non-CoViD-19 hospitalised patients. Over the improvement of communication, they can be relevant in supporting the maintenance of a culture of family centred care among healthcare professional, during a pandemic that undermined all aspects of patients' care.

Family members must be given clinical information at least once a day, and more often in case of any substantial and unexpected deterioration in the patient's condition

Information must be provided daily ${ }^{12}$ via any technological tools agreed between the healthcare professionals and the relatives, based on their preferences. If a video call between relative and patient is planned, both should be prepared in advance, especially in case of other painful events in the family.

Clinical information should always be communicated to the family by the same doctor

To ensure continuity, the same doctor should be always involved in communication whenever possible. During a video call, the speaker's face should be visible. When possible another healthcare worker should be present or connected remotely. Nursing staff should be included in conversation. ${ }^{31}$

When possible, any healthcare professional who feels that $s /$ he is not fit to bear the emotional burden of communicating at that time should be exempted from the task.

If a healthcare worker considers him/herself temporarily unable to make a phone call, consistently with resources, s/he should be permitted to honestly express discomfort and ask for help from available colleagues. In case of persistent difficulties, psychological support must be ensured.

Healthcare professionals' mental and emotional well-being must be taken into consideration and protected

Emotional fatigue may compromise the healthcare worker's ability to act effectively and efficiently. ${ }^{32}$ They should, therefore, be encouraged to admit this and to tackle it with the support of team colleagues and with psychologists, both coming from hospital clinical staff or from external on-line services.

Healthcare professionals should decide with the hospital management how to organise communications with relatives

All the different communication tools may be used for communicating between doctor and family members, or between patient and families. Concerning the connected legal issues, the different communication tools should be first agreed with hospital management.

Communicating by email/text message can be useful to enable relatives to have another careful look at the patient's information at a time suitable to them.

If the patient is in an ICU, a standard introductory email from the ward ${ }^{8}$ can be sent, followed up by personalised emails regarding the specific patient.

Communication must be unequivocal, truthful, well argued and commensurate with the recipient's ability to understand, their emotional state and life situation, with particular attention to frailty (eg, elderly family members, language barriers or mental disorders)

Speak honestly and sensitively, avoiding technical language and euphemisms. Clarify misunderstandings. Suggest hope without creating or encouraging unrealistic expectations. Evaluate the need for a cultural mediator. 3334 


\section{FAMILY PHONE CALL OPERATING FORM}

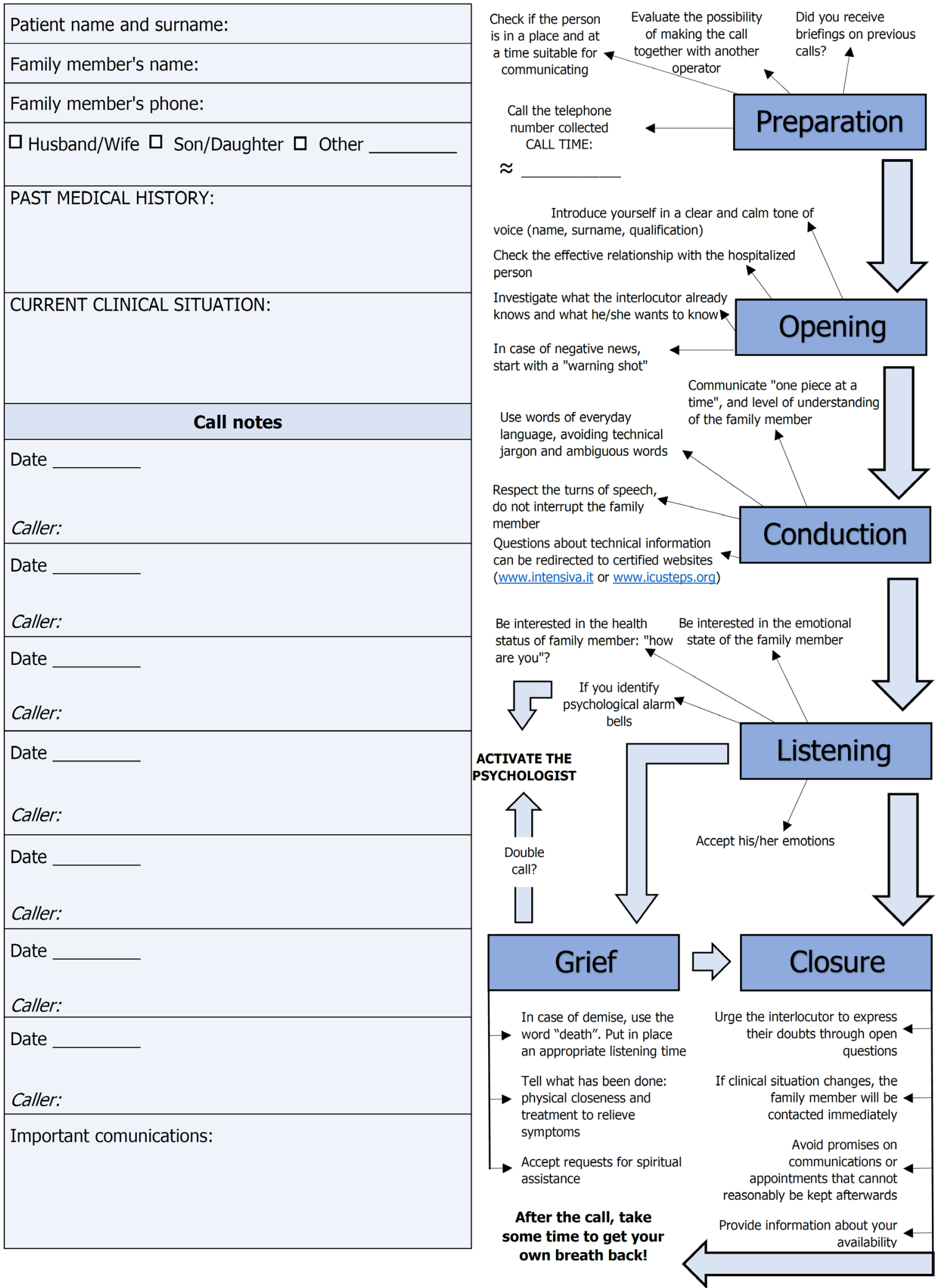

Figure 4 Family phone call operating form. SIAARTI, Italian Society of Anaesthesia and Intensive Care; Aniarti, Italian Critical Care Nurses Association; SICP, Italian Society of Palliative Care; SIMEU, Italian Society of Emergency Medicine. 


\section{CHECKLIST FOR VIDEO CALLS BETWEEN PATIENTS AND FAMILY MEMBERS}

Patient's name and surname

Name, surname of the family member

Contact details of the family member

\begin{tabular}{l|l|} 
V1 & \multicolumn{2}{|c|}{ Arranging the call with the family member } \\
V1.1 & Agree to a specific time for the call \\
\hline V1.2 & Suggest sitting in a quiet place. \\
\hline V1.3 & Agree whether children should be present. \\
\hline V1.4 & $\begin{array}{l}\text { Inform the person receiving the call that the video call must } \\
\text { be brief. }\end{array}$ \\
\hline V1.5 & $\begin{array}{l}\text { Patients not able to express themselves (e.g. intubated): } \\
\text { warn the person answering the call not to ask questions } \\
\text { requiring a complex replay. }\end{array}$ \\
\hline V1.6 & $\begin{array}{l}\text { Suggest that family members think beforehand about what } \\
\text { they want to say. }\end{array}$ \\
\hline V2 & Preparing the patient \\
\hline V2.1 & $\begin{array}{l}\text { Inform the patient (if conscious) that the video call will be } \\
\text { brief. }\end{array}$ \\
\hline V2.2 & $\begin{array}{l}\text { Reassure the patient (if conscious) that s/he will not be left } \\
\text { alone during the call. }\end{array}$ \\
\hline V2.3 & $\begin{array}{l}\text { Optimize position and lights; cover the patient's body } \\
\text { adequately. }\end{array}$ \\
\hline V2.4 & Consider lowering the volume of alarms. \\
\hline V2.5 & $\begin{array}{l}\text { Enable patients to see themselves, and ask again if s/he } \\
\text { wants to do the video call }\end{array}$ \\
\hline
\end{tabular}

\begin{tabular}{l|l|} 
V3 & Preparing staff \\
\hline V3.1 & Inform the team that a video call is about to take place. \\
\hline V3.2 & If appropriate, involve other professionals. \\
\hline V3.3 & Check your appearance. \\
\hline V3.4 & $\begin{array}{l}\text { If possible, remain with your face uncovered, wearing your } \\
\text { identification tag. }\end{array}$ \\
\hline V3.5 & Call the family member at the prearranged time. \\
\hline
\end{tabular}

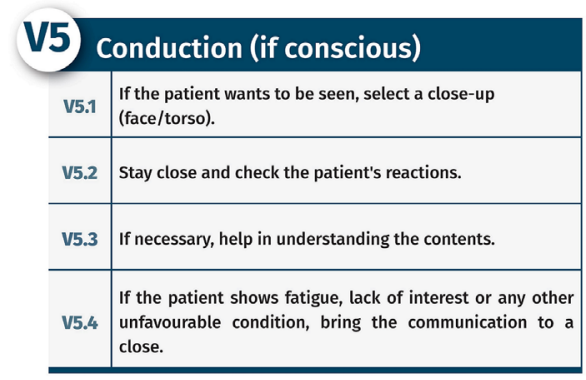

\section{V6 Conduction (if not conscious)}

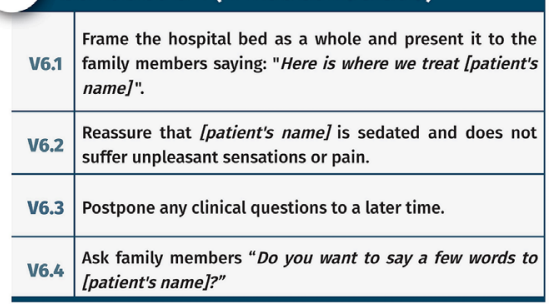

\section{V7) Closing}

V7.1 Thank the patient (if $\mathrm{s} / \mathrm{he}$ is conscious) telling him/her you will be back soon.

V72 Make yourself available to family members to clarify any

V7.2 doubts or answer questions.

Ask family members "How are you feeling?" and let them

V7.3 express their emotions.

V7.4 Use expressions of sympathy: "I imagine it must be very V7.4 difficult".

V7.5 End by agreeing, if appropriate, on a later video call.

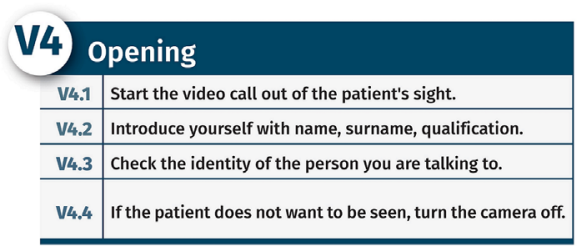

Figure 5 Checklist for video calls between patients and family members.

Reconstruct the patient's preferences and values, also through a dialogue with family members, to respect his self-determination

Respect for autonomy is essential and must always be maintained. Therefore, as far as possible, informed consent should be requested, shared care planning implemented and any advance healthcare directive respected. The preferences and values of patients should be reconstructed with family members, too. ${ }^{35} 36$

Give full information about pain control

It is essential to reassure the family that palliative treatment of distressing symptoms is a goal that is constantly pursued and achieved even in the most challenging stages of care.

Leave room for and welcome the relatives' emotions

If there is any very intense emotional reaction, or difficulty in adapting to the situation (denial, aggression), it is advisable to suggest support from a psychologist, and be ready to ask for it. 


\section{Checklist for phone calls to the family members}

During a pandemic, the telephone is the most used and straightforward tool of communication between healthcare professionals and patient's families. However, it is relevant to note that communicating by phone in regard of a patient in isolation in an unstable or severe clinical condition is a challenging task for all: doctors, nurses and family members frequently present the previously described emotional burdens.

The authors agreed to provide a checklist based on a consensus procedure for adequately organising and successfully conducting a phone call with the family members. Thus, they have identified and discussed six topics (preparation, opening, conduction, listening, managing grief, closure) and, for each of them, five items aimed to prepare and structure the phone call.

\section{Preparation}

Healthcare professionals must know the name and surname of the patient and family member, and be aware of the patient's current clinical conditions and past medical history.

It is preferable to organise a quiet place for the call. Check all the technical equipment before calling.

If the healthcare worker who is calling needs to be changed during the week, include in the handover data on communication with family members (contact person, family resources, content, critical issues).

When possible make the call together with another healthcare worker connected remotely both for greater effectiveness and feedback.

In order to avoid anxiety-provoking expectations call the telephone number indicated at admission and at a pre-established time.

\section{Opening}

Introduce yourself in a clear and calm tone of voice (name, surname, qualification).

Ask to speak with the person identified as the contact person, referring to him by name and surname, and checking his effective relationship with the hospitalised person.

In case of potentially vulnerable family (elderly, foreigners, people with psychiatric disorders): propose to disclose clinical information to a third person at home, who can act as an intermediary.

Before starting, check if the person is in a place and at a time suitable for communicating.

Find out what the interlocutor already knows and what $\mathrm{s} /$ he wants to know. ${ }^{37}$ In case of negative news, start with a warning shot (eg, 'I have to warn you that unfortunately I have no good news...').

Conducting the call

Communicate 'one piece at a time', gradually presenting the clinical severity in order to adapt the information to the needs and level of understanding of the family members.

Frequently assess the understanding of what has been said, also through the interlocutor's emotional reactions; when in doubt, invite them to tell you what they have understood.

Use simple, short sentences and everyday language, avoiding technical and scientific jargon and ambiguities. ${ }^{38}$

Pay attention to listening to whoever is answering. Do not interrupt the family member and accept interruptions without getting impatient. ${ }^{39}$

Questions about technical information on ICUs can be redirected to certified websites. ${ }^{40}$

Listening

Show interest in the emotional state of the family member. Detecting and recognising emotions as legitimate enables you to create trust and therapeutic alliance. $^{41}$

Give the prognostic estimate honestly in response to an explicit request from the family member. It should be specified that the prognosis is merely an estimate, and may well change.

Welcome the interlocutor's emotional response (fear, sadness, anxiety, anger), both through silence and by allowing the interlocutor to cry or make verbal outbursts. $^{42}$

Psychological alarm bells: if you notice very intense emotional reactions or fatigue in adapting to the clinical situation (negation, aggression), it is advisable to offer psychological support and make yourself available to activate it.

Be interested in the healthcare situation of family members, both psychological and physical.

\section{Managing grief}

When a patient dies, use the word 'death'. Allow for an appropriate listening time, before providing clinical/organisational indications. In the event of a critical clinical condition, replace the word 'serious' with unequivocal phrases (eg, 'need to prepare for the worst').

Welcome the emotions of the interlocutor, keeping silent and listening. ${ }^{43}$

In case of death, make it clear that even though the treatments were ineffective, patient care was never interrupted, both in terms of physical proximity (eg, 'your husband was isolated, but never left alone'), and in terms of treatment aimed at relieving pain or other symptoms of suffering.

Accept requests for religious assistance and facilitate their implementation. ${ }^{23}$

In case of death, consider whether to make two calls. In the first one, the doctor reports the death. In the second, another healthcare worker (nurse or psychologist ${ }^{44}$ gathers the grief, helps the person(s) process the loss in conditions of distance and isolation, verifies the 
family's spontaneous psychoemotional resources and supports them.

\section{Closure}

Solicit the person to express their doubts through open questions (eg, 'is there anything else you want to know?'). ${ }^{45}$

Offer suggestions for technological solutions for video calls, if requested.

Provide information on your availability (repeat your name and surname, department, your phone number). Specify that the next day she/he will be called again, at an agreed time, unless unexpected hospital emergencies arise.

Avoid promises of communication or appointments that cannot reasonably be kept: unfulfilled expectations break the bond of trust.

End the interview with reassurance that in the event of any major clinical changes, the family members will be promptly contacted by the healthcare professionals.

Figure 4 reports a family phone call operating form, to help physicians and allied healthcare staff in conducting a telephone call. It may also be used for handover about family communication.

Figure 5 shows a further checklist for videocalls. Since the systems to make this kind of communication are very common, but also they are particularly challenging, the care team should perform this type of communication only after adequate preparation.

\section{Study limitations}

The present Consensus Statement presents several limitations. First, it is based only on the expert opinion of the authors: even if there is a quite large body of literature on the topic of family communication, nothing has been pulished about it in the specific context of complete social isolation because of a pandemic. The consensus procedure was then built only on the authors opinion. Moreover, the statements' efficacy and usefulness have been not evauated prospectively in the real scenario, since the need for complete isolation had progressively end from May 2020. This could be an important study to do, in the unlucky case the social lockdown will become once again necessary.

Second, this Consensus Statement was prepared and written in the dramatic circustances of a pandemic peak with overcharged hospitals: a very short time was granted to the taskforce by the endorsing scientific societies, since the need for these statements were coming from healthcare professionals from all around Italy. Moreover, even if members of the expert panel were coming from 14 different Italian regions (on a total of 20), they are all Italian people, with cultural, social, legal background limiting the possibility to use the presented statements in other countries exactly as they are here presented and discussed.

Third, the physicians and nurses selected for the taskforce were all working in emergency or in critical care settings: neighter pneumolgists, epidemiologists, infectious diseases specialists, nor healthcare manager or religious authorities were involved. Furthermore, only the steering committee of four national scientific societies approved the document, without the evaluation of other scientific societies or other healthcare experts coming from other disciplines.

The presence into the taskforce of two previous ICU patients and two family members of patients admitted in ICU for CoViD-19 was very important and appreciated: they offered a very interesting interpretation of the reality, together with some useful indication to improve the communication quality.

\section{CONCLUSION}

The communication typical of the globalised world, during an overwhelming pandemic, can give way to an experience of silent solitude: the loneliness of the patient and anguished isolation of family members and of healthcare professionals within their hospitals.

A phone call, a video call, an email, a written story try to replace the physical contact that the isolation prohibits: communicating with the family allows people to create a listening space where worries, anguish of death and fears are collected for themselves and their loved ones far away, and in which they try to build trust and hope.

It is crucial to establish contact with family members. A well-conducted phone call by the doctor on the clinical conditions, in a daily communication round, becomes a tool to care for those who cannot personally see their loved one, who suffer the anxiety of not having direct information and, often, ease the sense of guilt linked to 'the feeling of abandoning his/her own loved one'.

We inform, reassure, collect tears and together we build the hope for containing and eventually overcoming a psychological trauma that will leave its marks in future years. Otherwise we end up accompanying the pain of a death without closeness and with no direct participation, but at least not loneliness.

The time dedicated to communication has to be intended as a time of care. As such, it emerges as a whole area of expertise and demands the same high level of knowledge and competence as all other areas of clinical practice. If this is true and experienced in 'normal' conditions, it is much more important in the dramatic emergency conditions spawned by the SARS-CoV-2 pandemic. The experience we withnessed during the pandemic gives us a clear indication that the time has come to include communication in the pregraduation and postgraduation curricula of our schools of medicine. 


\section{Author affiliations}

1Dipartimento di Fisiopatologia Medico-Chirurgica e dei Trapianti, Università degli Studi di Milano, Milano, Italy

${ }^{2}$ SC Anestesia e Rianimazione, Ospedale San Paolo - Polo Universitario, ASST Santi Paolo e Carlo, Milano, Italy

${ }^{3}$ Società Italiana Anestesia Analgesia Rianimazione e Terapia Intensiva (SIAARTI), Roma, Italy

${ }^{4}$ Educational Services for Health and Social Development, Officina

Comunicativa, Treviso, Italy

${ }^{5}$ Department of Intensive Care and Anesthesia, Central Hospital of Macerata, Macerata, Italy

${ }^{6}$ General and Neurosurgical ICU, Ospedale dell'Angelo, Aulss 3 Serenissima Veneto, Venezia, Italy

${ }^{7}$ Department of Palliative Care, Azienda USL di Piacenza, Piacenza, Italy

${ }^{8}$ Anestesia e Rianimazione 1, ASST Spedali Civili, Brescia, Italy

${ }^{9}$ UOC Anestesia Rianimazione 1 Dip.to Emergenza Accettazione, A. O. San Camillo-Forlanini, Roma, Italy

${ }^{10}$ Dipartimento di Scienze dell'Emergenza, Anestesiologiche e della Terapia Intensiva, Fondazione Policlinico Universitario A. Gemelli IRCCS, Roma, Italy

${ }^{11}$ UOC Anestesia e Rianimazione, Ospedale di Belluno, Aulss 1 Dolomiti, Belluno, Italy

${ }^{12}$ Intensive Care Unit, AOU S. Maria della Misericordia, Perugia, Italy

${ }^{13}$ Direction of Healthcare Professions, Foundation IRCCS Ca' Granda Ospedale Maggiore Policlinico, Milano, Italy

${ }^{14}$ Terapia Intensiva, IRCCS San Raffaele Hospital, Milano, Italy

${ }^{15}$ Emergency Department, Martini Hospital, ASL Città di Torino, Torino, Italy

${ }^{16}$ Department of Health Sciences, Università degli Studi di Milano, Milano, Italy

${ }^{17}$ UOC Clinical Psychology, ASST Santi Paolo e Carlo, Milano, Italy

${ }^{18}$ Servizio Psicologia Ospedaliera, Fondazione Policlinico Universitario A. Gemelli IRCCS, Roma, Italy

${ }^{19}$ Dipartimento di Neuroscienze, Azienda Ospedaliera G Brotzu, Cagliari, Italy

${ }^{20}$ Psycho-oncology Unit, Azienda USL - IRCCS di Reggio Emilia, Reggio Emilia, Italy

${ }^{21}$ Avvocato, Foro di Milano, Milano, Italy

${ }^{22}$ Department of Political Science, Law and International Studies, Università degli Studi di Padova, Padova, Italy

${ }^{23}$ ICU 4, AO San Camillo-Forlanini, Roma, Italy

${ }^{24}$ Unit of Pediatric Anesthesia and Intensive Care, Children's Hospital, ASST

Spedali Civili, Brescia, Italy

${ }^{25}$ Department of Anesthesia and Intensive Care, San Giovanni Bosco Hospital, Torino, Italy

${ }^{26}$ Società Italiana Anestesia Analgesia Rianimazione e Terapia Intensiva

(SIAARTI), Napoli, Italy

${ }^{27}$ Department of Anesthesiology and Intensive Care, University of L'Aquila,

L'Aquila, Italy

${ }^{28}$ UO Anestesia e Rianimazione 1, Ospedale Santa Chiara, Trento, Italy

${ }^{29} 118$ Empoli, Azienda USL Toscana Centro, Empoli, Italy

${ }^{30}$ Associazione Nazionale Infermieri di Area Critica (Aniarti), Udine, Italy

${ }^{31}$ Educational Services for Health and Social Development, Officina

Comunicativa, Torino, Italy

${ }^{32}$ Department of Molecular Medicine, Università degli Studi di Padova, Padova, Italy

${ }^{33}$ Avvocato, Foro di Bologna, Bologna, Italy

${ }^{34}$ Dipartimento di Scienze del Linguaggio e Letterature moderne e comparate, Università degli Studi di Torino, Torino, Italy

${ }^{35}$ Accademia delle Belle Arti di Brera, Milano, Italy

${ }^{36}$ Restauratrice, Milano, Italy

${ }^{37}$ Dipartimento Emergenza Urgenza, Ospedale Sandro Pertini, Roma, Italy

${ }^{38}$ SC Medicina e Chirurgia di Accettazione e di Urgenza, Ospedale di Oristano, Oristano, Italy

${ }^{39}$ Società Italiana di Cure Palliative (SICP), Milano, Italy

${ }^{40}$ DATeR Processo Assistenziale nelle Cure Palliative, Azienda USL di Bologna,

Bologna, Italy

${ }^{41}$ Dipartimento Infermieristico e delle professioni tecnico sanitarie, IRCCS

Istituto Giannina Gaslini, Genova, Italy

${ }^{42}$ UOC Anestesia e TIPO, Azienda dei Colli, Ospedale Monaldi-Cotugno, Napoli, Italy

${ }^{43}$ Perioperative Medicine, Pain Therapy, ICU and Emergency Department, ASL2 -

Chieti Pescara University, Chieti, Italy

Acknowledgements The authors are very grateful to the physicians and nurses participating to the Project Intensiva
2.0 for their essential cooperation. This paper endorses the Humanisation to Enhance Recovery On Intensive Care bundle (www.heroicbundle.org). We are grateful to Katrien Devolder and Thomas Douglas, Oxford, for language editing, and to Carlotta Moreschi, Milano, for help in drafting figures.

Contributors GM and FP conceived the study. GM, GG, SM, EI, IG, SB, FF, GF, EF, MB, DM, GDG, AG, AN, FDI, EG, GL, SDN, LM, FS, SDL, NG and MP deeply discussed and wrote the first version of consensus statements. LR, AG, SL, CM, MV, FM, LL, AM, ED, EV, SC, AA, GL, LF, GC, CA, FP, SM, LO, FM, SS, AC and FP revised the statements for important intellettual contents. All authors participated and voted in the e-Delphi procedure. GM and GG wrote the first version of the present manuscript, that was substantially modified by EI, IG, FF, MB, GDG, AG, GL, SDN, NG, MP, AG, MV, AM, EV, LO, FM, FP. All authors have read and approved the final version and submission of the present manuscript to BMJ Supportive and Palliative Care.

Funding The authors did not received any specific grant for this research from any funding agency in the public, commercial or not-for-profit sectors.

Competing interests None declared.

Patient consent for publication Not required.

Provenance and peer review Not commissioned; externally peer reviewed.

Data availability statement All data relevant to the study are included in the article or uploaded as supplementary information.

Open access This is an open access article distributed in accordance with the Creative Commons Attribution Non Commercial (CC BY-NC 4.0) license, which permits others to distribute, remix, adapt, build upon this work noncommercially, and license their derivative works on different terms, provided the original work is properly cited, appropriate credit is given, any changes made indicated, and the use is noncommercial. See: http://creativecommons.org/licenses/by-nc/4. $0 /$.

ORCID iD

Giovanni Mistraletti http://orcid.org/0000-0001-8322-1623

\section{REFERENCES}

1 Cluver L, Lachman JM, Sherr L, et al. Parenting in a time of COVID-19. Lancet 2020;395:e64.

2 Giannouli V, Mistraletti G, Umbrello M. ICU experience for patients' relatives: is information all that matters? : Discussion on "A family information brochure and dedicated website to improve the ICU experience for patients' relatives: an Italian multicenter before-and-after study". Intensive Care Med 2017;43:722-3.

3 Benatti SV. Love in the time of corona. Ann Intern Med 2020;172:628.

4 Scheunemann LP, McDevitt M, Carson SS, et al. Randomized, controlled trials of interventions to improve communication in intensive care: a systematic review. Chest 2011;139:543-54.

5 Curtis JR, White DB. Practical guidance for evidence-based ICU family conferences. Chest 2008;134:835-43.

6 Levin TT, Moreno B, Silvester W, et al. End-of-life communication in the intensive care unit. Gen Hosp Psychiatry 2010;32:433-42.

7 Davidson JE, Aslakson RA, Long AC, et al. Guidelines for family-centered care in the neonatal, pediatric, and adult ICU. Crit Care Med 2017;45:103-28.

8 Mistraletti G, Mezzetti A, Anania S, et al. Improving communication toward ICU families to facilitate understanding and reduce stress. protocol for a multicenter randomized and controlled Italian study. Contemp Clin Trials 2019;86:105847. 
9 Aguilar F. Scanning the business environment. New York, NY: MacMillan edn, 1967.

10 Topor DR, Dickey C, Stonestreet L, et al. Interprofessional health care education at academic medical centers: using a SWOT analysis to develop and implement programming. MedEdPORTAL 2018;14:10766.

11 Warrillow S, Farley KJ, Jones D. How to improve communication quality with patients and relatives in the ICU. Minerva Anestesiol 2016;82:797-803.

12 Black MD, Vigorito MC, Curtis JR, et al. A multifaceted intervention to improve compliance with process measures for ICU clinician communication with ICU patients and families. Crit Care Med 2013;41:2275-83.

13 Langeron $\mathrm{O}$, Monsel A. Communication with patients and relatives in ICU: a skill to master. Minerva Anestesiol 2016;82:733-4.

14 Quintel M. "I feel how you feel": reflections about empathy in the relationship between ICU physicians and relatives. Intensive Care Med 2017;43:1723-4.

15 Turnbull AE, Chessare CM, Coffin RK, et al. A brief intervention for preparing ICU families to be proxies: a phase I study. PLoS One 2017;12:e0185483.

16 Vergano M, Bertolini G, Giannini A, et al. SIAARTI recommendations for the allocation of intensive care treatments in exceptional, resource-limited circumstances. Minerva Anestesiol 2020;86:469-72.

17 Vergano M, Magavern E, Zamperetti N. Clinical ethics: what the anesthesiologist and the intensivist need to know. Minerva Anestesiol 2018;84:515-22.

18 Rosenbaum L. Facing Covid-19 in Italy - Ethics, Logistics, and Therapeutics on the Epidemic's Front Line. N Engl J Med 2020;382:1873-5.

19 Thompson IE. The nature of confidentiality. J Med Ethics 1979;5:57-64.

20 Cicekci F, Duran N, Ayhan B, et al. The communication between patient relatives and physicians in intensive care units. BMC Anesthesiol 2017;17:97.

21 Azoulay E, Chaize M, Kentish-Barnes N. Involvement of ICU families in decisions: fine-tuning the partnership. Ann Intensive Care 2014;4:37.

22 Courtright KR, Benoit DD, Halpern SD. Life after death in the ICU: detecting family-centered outcomes remains difficult. Intensive Care Med 2017;43:1529-31.

23 Cook D, Rocker G. Dying with dignity in the intensive care unit. N Engl J Med 2014;370:2506-14.

24 Schwarzkopf D, Behrend S, Skupin H, et al. Family satisfaction in the intensive care unit: a quantitative and qualitative analysis. Intensive Care Med 2013;39:1071-9.

25 Roeland E, Cain J, Onderdonk C, et al. When open-ended questions don't work: the role of palliative paternalism in difficult medical decisions. J Palliat Med 2014;17:415-20.

26 Parker AM, Bienvenu OJ. Posttraumatic stress disorder symptoms among family decision makers and the potential relevance of study attrition. Crit Care Med 2015;43:1334-5.

27 Scheunemann LP, Ernecoff NC, Buddadhumaruk P, et al . Clinician-family communication about patients' values and preferences in intensive care units. JAMA Intern Med 2019;179:676-84.

28 Gristina GR, Busatta L, Piccinni M. The Italian law on informed consent and advance directives: its impact on intensive care units and the European legal framework.

Minerva Anestesiol 2019;85:401-11.

29 PrivazyPlan ${ }^{\circledR}$. EU general data protection regulation 2016/679 (GDPR) Article 9. "Processing of special categories of personal data". Available: https://bit.ly/3dsw8Xg [Accessed 18 May 2020].

30 PrivazyPlan ${ }^{\circledR}$. EU general data protection regulation 2016/679 (GDPR) Article 5. "Principles relating to processing of personal data". Available: https://bit.ly/2WKobGf [Accessed 18 May 2020].

31 Lautrette A, Darmon M, Megarbane B, et al. A communication strategy and brochure for relatives of patients dying in the ICU. N Engl J Med 2007;356:469-78.

32 Sanchez-Reilly S, Morrison LJ, Carey E, et al. Caring for oneself to care for others: physicians and their self-care. $J$ Support Oncol 2013;11:75-81.

33 Baile WF, Buckman R, Lenzi R, et al. SPIKES-A six-step protocol for delivering bad news: application to the patient with cancer. Oncologist 2000;5:302-11.

34 Van Keer R-L, Deschepper R, Francke AL, et al. Conflicts between healthcare professionals and families of a multi-ethnic patient population during critical care: an ethnographic study. Crit Care 2015;19:441.

35 Lind R, Lorem GF, Nortvedt P, et al. Family members' experiences of "wait and see" as a communication strategy in end-of-life decisions. Intensive Care Med 2011;37:1143-50.

36 Kleinpell R, Zimmerman J, Vermoch KL, et al. Promoting family engagement in the ICU: experience from a national collaborative of 63 ICUs. Crit Care Med 2019;47:1692-8.

37 Lilly CM, Daly BJ. The healing power of listening in the ICU. N Engl J Med 2007;356:513-5.

38 Mistraletti G, Umbrello M, Mantovani ES, et al. A family information brochure and dedicated website to improve the ICU experience for patients' relatives: an Italian multicenter before-and-after study. Intensive Care Med 2017;43:69-79.

39 McDonagh JR, Elliott TB, Engelberg RA, et al. Family satisfaction with family conferences about end-of-life care in the intensive care unit: increased proportion of family speech is associated with increased satisfaction. Crit Care Med 2004;32:1484-8.

40 Nguyen Y-L. Dealing with Internet-based information obtained by families of critically ill patients. Intensive Care Med 2019;45:1119-22.

41 Di Bernardo V, Grignoli N, Marazia C, et al. Sharing intimacy in "open" intensive care units. J Crit Care $2015 ; 30: 866-70$

42 Seaman JB, Arnold RM, Scheunemann LP, et al. An integrated framework for effective and efficient communication with families in the adult intensive care unit. Ann Am Thorac Soc 2017;14:1015-20.

43 Maynard DW. Delivering bad news in emergency care medicine. Acute Med Surg 2017;4:3-11.

44 Curtis JR, Treece PD, Nielsen EL, et al. Randomized trial of communication facilitators to reduce family distress and intensity of end-of-life care. Am J Respir Crit Care Med 2016;193:154-62.

45 Cox CE, Jensen HI. The unmet need of information access for family members of ICU patients. Intensive Care Med $2017 ; 43: 240-2$. 